\title{
Enterprise architecture approach to mining companies engineering
}

\author{
Igor Ilin ${ }^{1, *}$, Anastasia Levina ${ }^{1}$, and Oksana Iliashenko $^{1}$ \\ ${ }^{1}$ Peter the Great Saint-Petersburg Polytechnic University, Polytechnicheskaya, 29, St.Petersburg, \\ 195251, Russia
}

\begin{abstract}
As Russian economy is still largely oriented on commodities production, there are a lot of cities where mining and commodity-oriented enterprises are the backbone of city economy. The mentioned enterprises mostly define the life quality of citizens in such cities, thus there are high requirements for engineering of city-forming enterprises. The paper describes the enterprise architecture approach for management system engineering of the mining enterprises. The paper contains the model of the mining enterprise architecture, the approach to the development and implementation of an integrated management system based on the concept of enterprise architecture and the structure of information systems and information technology infrastructure of the mining enterprise.
\end{abstract}

\section{Introduction}

Because of the commodity nature of Russian economy as a whole and a lot of Russian cities particularly, it is crucially important to provide the effective engineering of mining and other natural resources-oriented companies in order to provide their efficiency and sustainable development from the very beginning. As backbone of city economy, main taxpayers and main employers, mining and commodity-oriented companies create main prerequisites for sustainable urban development in so called one-company towns.

The competitive level of the mining enterprise depends not only on the stocks of raw material, production volume, advanced equipment and technology, but also the quality of enterprise management as a modern business at all stages of the life cycle. The most important component of the enterprise management system nowadays is information system that allows to collect information, conduct analysis and make decisions on a whole new level. Automation of the enterprise is a serious challenge to the business, because it requires a systematic approach to designing IT solutions involving a large number of enterprise subsystems and all levels of management [1].

Modern mining production is impossible without automation, that is why the individual components of the Integrated Management System (IMS), in a minimum volume, should be already developed at the stage of development of project documentation for construction. In particular, part of the technological equipment by default is supplied complete with a local automated control systems. However, in the absence of a unified concept of creating the

*Corresponding author: ivi2475@gmail.com 
IMS and clear procedure of managing its implementation, adopted on the early stages of the project of a new enterprise, you may experience the following problems [2-4]:

- spontaneous implementation of various subsystems of information system at different periods of time;

- inconsistency of decisions of the various developers and, as a consequence, inability to further integrate separate subsystems into a single IMS;

- increased costs for the implementation of individual subsystems;

- achieving local optima to the detriment of the effectiveness of the entire management system;

- lack of capabilities of replication, scaling, modernization and expansion of the functionality of the automated control systems as enterprise develops;

- inability of flexible optimization of the process chain;

- use of solutions that put the customer in dependence of the particular performers and producers during the operational phase;

- increase of operational costs.

During the construction phase all this entails an increase of the risk of delay of the enterprise commissioning and output on a project capacity.

At the existing production, fragmentation of the automated systems leads to:

- subjectivity and significant influence of the human factor on the collection and interpretation of information;

- $\quad$ significant costs to identify the true state of affairs;

- decision-making based on distorted information;

- tendency to spontaneous deviations management;

- permanent overestimation of planned costs for all components of the production process;

- reduce of the efficiency of the enterprise's operating activity.

The use of a systematic approach to the development and implementation of the IMS allows to avoid the above problems and to minimize the associated risks. Systematic approach in this case involves not only a holistic view of enterprise automation problems, but also the consideration of a corporate information system in the context of the overall business management system.

The realization of the IMS project, synchronized with the master plan of the project of construction of the enterprise, will eliminate a lot of problems previously encountered with the creation, integration and development of automated systems, to build a business model and efficient enterprise management system, and to reduce future costs for the modernization of production and service.

The paper describes an approach based on enterprise architecture concepts and methodology of development and implementation of integrated management systems for the mining companies.

\section{Method}

Creating a mining company from the green field, there is a unique opportunity to make a reliable and in the meantime flexible foundation for an enterprise based on such kind of management technologies, that will ensure the efficient running of business in the future. Many design institutes and engineering companies are involved into designing of mining enterprises. These organizations offer a wide range of services on engineering survey, design, industrial construction, supervision and consulting of established mining companies. Analysis of the information about the services on the web-sites of the largest Russian design institutes allowed to form the following list of proposed works: development of geological, technological, constructional and mechanical parts of the 
mining industry projects; technological design of repair and storage facilities and ancillary facilities; design of automated system of technological processes control on enterprise. These types of work are regulated by the relevant regulatory documents (including state standards), technology of their implementation has been perfected for decades, making the Russian market participants of these services very competitive.

These types of work are targeted at the creation of the material embodiment of the future enterprise. According to the designed projects there will be constructed buildings, constructions, aggregates, infrastructure of processing material resources into finished products - all this will make "flesh" and "material stuffing" of the enterprise. However, none of the Design Institutes talk about the design of "brain" and "neural networks" of enterprise - complex targeted business management system. In the development of project documentation for the construction of mining and processing enterprises, control and automation issues are usually overlooked. Legal documents in Russia, including Government Decree №87 «On the composition of project documentation and requirements to their content", almost do not regulate these questions. Main State Expertise of Russia also does not require processing solutions on complex business management, including automation and application of information technology (except for the description of security systems). Problem of imperfection of management system is particularly acute arises in the newly established enterprises. Besides, here it is important not only to have an effective management system on the stages of the output to planned production capacity and further operation, but also the proper management of the organization of work on the stages of creation of the enterprise (design, construction, commissioning and start-up). [5]

Designing and building business is a more complicated than designing production. Nowadays, there is no a single accepted standard for the design and creation of business. At the moment all around the world, modern organizational technologies, called business engineering, are used to solve such problems. Business engineering uses in the management those achievements that successfully operate in the design and management of technical objects, and allow to make management accurate and effective [6]. This method of designing organization is realized with the help of special software which is analogue of CAD systems for technical design. In the business engineering priority is given to preliminary "design" of companies based on accurate models of their performance, which eliminates most of the problems of enterprise operational management.

The key concept of business engineering is the concept of enterprise architecture. The concept of "architecture" initially appeals to the understanding and definition of the relationship between the users of a system and the actual system itself. Understanding these relationships and consequently the requirements for the system, allows to define the essence of the system, i.e., structure, behaviour, and other properties [7]. This "substance", often referred to as the system architecture is the basis for the analysis, evaluation and optimization and is the starting point for the design, creation and implementation of the system. Enterprise architecture model is designed to bring together technologies of managing various aspects of businesses to create an integrated management system.

Currently, the enterprise architecture is widely used as a systematic management approach, understanding by this term a set of different elements of the management structure and the relationship between them (various definitions can be found in [8-11]). Enterprise architecture in its modern sense emerged as a response to the problem of alignment of business needs and IT infrastructure (according to [7, 12]).

Traditionally, elements of enterprise architecture are grouped into so-called layers, the number and the names of which vary in different sources (for example, [7, 12-13]), but the overall approach and the composition of the elements of the enterprise architecture are very similar. For example, in [12] the following layers are identified:

- corporate mission and vision, strategic goals and objectives; 
- business architecture: business processes, organizational structure and staffing, work flows;

- system architecture (IT architecture): applications, data, hardware.

TOGAF approach [12], which has become the de facto standard for the development of architectural solutions, offers the following layers of enterprise architecture:

- business layer (business processes, organizational structure);

- application layer: information systems and applications;

- technology layer: IT infrastructure, database.

The paper is based on the concept of enterprise architecture and the achievements of business engineering.

\section{Results}

In order to create an approach to the design of the IMS of mining enterprises, the following model of enterprise architecture (Figure 1) was proposed.

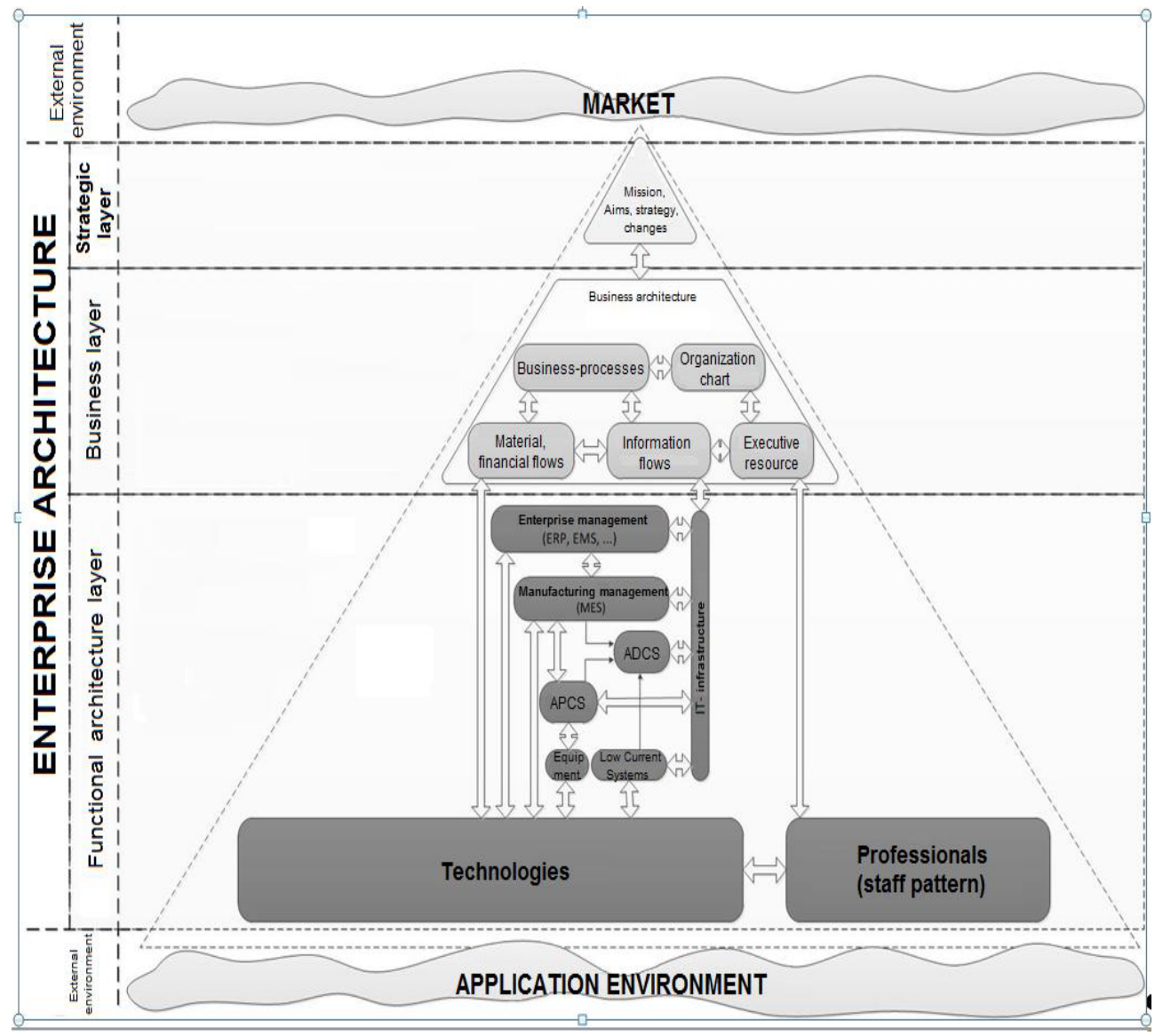

Fig. 1.Enterprise architecture model of a mining company.

Figure 1 highlights the following elements of the enterprise architecture and the relationships between them:

1. Strategic layer - mission, vision and strategy of the company, which correspond to the needs of the market; 
2. Business layer:

- business processes - a system of organization of activities of the company that determines the other elements of the business layer;

- organization chart (organizational structure);

- material and financial flows - flows of material resources and cash generated by the company's business processes on the one hand and technology of the specific subject area - on the other;

- information flows - most part of the flow of information is embodied in the form of documents;

- executive resource - specialists, intelligent agents, etc.

3. A layer of functional architectures:

- Enterprise Management System (ERP, etc.);

- Manufacturing Execution System (MES);

- Automated dispatch control system (ADCS);

- Automated process control system (APCS);

- Equipment - measuring instruments and automation;

- low-current systems - communication, security systems, etc.;

- IT-infrastructure;

- technology - the technological processes of production, as well as related material and technical base of the enterprise;

- staff pattern- required in accordance with the technologies professional staff.

In contrast to the common enterprise architecture models [7, 12-13], instead of the application layer and the layer of the IT infrastructure, stands a broader concept - a layer of functional architectures. This layer defines not only the architecture of the IT components, but the architecture of production technology, specific to each sector, which is an integral part and a key element of any enterprise.

The enterprise architecture approach to the design and engineering of the company involves the development and subsequent implementation of interconnection of all elements of the enterprise management system, which is reflected in an enterprise architecture model [14].

When designing mining enterprises in parallel with the project documentation it is advisable to carry out the development of complex of enterprise management solutions that include not only control system of layer of functional architectures (AS, IT, MES, EAM, ERP), but also higher systems of all business management levels (strategic layer and business layer).

Application of modern technologies of designing activity of the enterprise provides the following properties of a created management system:

- compliance with the strategic objectives and priorities;

- presence of a balanced scorecard and measurability of results;

- scalability and replicability of enterprises' models;

- transfer of 'best practices';

- complexity and balance of system components;

- transparency of the organization;

- relative independence of the "personalities";

- possibility of further development and improvement.

It is advisable to realize the following steps of creating the architecture of the mining companies, in accordance with the life cycle of the enterprise:

- In the design stage - architectural model of company's activity (objectives, indicators, key functions and business processes, staffing, IT, etc.);

- In the construction stage - business process model, regulatory documentation (provisions of subdivisions, job descriptions); 
- In the stage of reaching the design capacity - fixing engineered business processes, adjustment of operating regulations;

- In the stage of commercial operation - the accumulation of statistics, the fixation of best practices, the formation of the knowledge base of the company;

- In the stage of development - the concept of strategic development, targeted architectural model activity, program of development projects.

The main objectives of the development of the IMS are:

- ensuring a high level of reliability, performance and cost-efficiency of the company through a qualitative solution of problems of technological, operational and corporate management;

- creation of a unified MIS, including a range of solutions that meet customer requirements on optimum fulfilment of the individual enterprise management tasks;

- effective distribution of work and organization of coordinated activities of many contractors and suppliers within the framework of development, implementation, operation and modernization of the IMS.

To achieve these goals as early as possible it is necessary to ensure the fulfilment of the following tasks:

- identify a set of integrated solutions that meet customer requirements for optimum fulfilment of the individual enterprise management tasks;

- prioritize the implementation of individual subsystems and the stages of their creation in accordance to the plan of construction and expansion of facilities and engineering systems of a mining company;

- define the general principles and the creation of the IMS;

- define technical requirements to IMSoverall and its subsystems, including the requirements for the expansion of the IMSand the individual subsystems within the enterprise life cycle [15];

- develop a single technical specification for IMS, including private technical specifications for separate subsystems that specify requirements for them, their functions and tasks;

- develop technical projects for individual subsystems of the IMS;

- reconcile the rules of interaction between the customer, developers of the local control systems, supplied complete with technological equipment, designers, developers and suppliers of individual subsystems of the IMS;

- build reliable, scalable and productive infrastructure of information exchange;

- perform complex automation of technological, production and business processes of the company;

- unify and integrate processes of production management;

- build a unified information space of the mining enterprise management.

The solution of the above goals and objectives will improve the quality of monitoring and control activities of the enterprise at the expense of providing all employees of the company with timely and accurate information and convenient analytical decision support tools.

MIS of mining enterprise should cover all levels of management, in particular the layer of functional architectures, including:

- level of technological process management (first level);

- level of production management (second level);

- level of enterprise management (third level).

Problems of managing main technological aggregates and chains are solved on the first level. This provides current control of parameters and managements in real time (or nearly real time). 
Systems of the second level, on the one hand, perform functions on managing the product creation chain, on the other, ensure the transparency of the planning and control of production activities and the associated costs, including:

- accurate planning of production and the need for material resources in the medium-term (year, quarter) and the short-term (one month) horizons;

- account of movement of material flows and organization of uninterrupted receipt of material and technical resources and technological materials for the main technological chain of production;

- account of finished products on the main process stages of the production chain and the organization of the delivery of metals to the place of shipment;

- account and quality control of raw materials, semi-finished and finished products, starting from the quarries across the whole technological chain;

- management of fixed assets, planning and realization of maintenance and repair of equipment, optimization of costs for maintenance of fixed assets, while maintaining the required level of reliability and performance;

- account and timely provision of accurate production information to the top-level system for calculation of the actual results of the company.

The third level consists of administrative, financial, accounting and tax accounting, human resources management, procurement systems, as well as specialized solutions for business analysis and strategic planning.

It should be noted that mining companies often focus on systems of first (technological process management) and third (enterprise management) levels. [16-17]The level of production management, as a rule, remains out of sight. At the same time, systems of this level are a critical element of MIS in company.

\section{Conclusion and Discussion}

Successful and efficient running business by city-forming enterprises creates a foundation for a sustainable development of such kind of cities. In mining science and practice it is becoming more urgent to automate production and provide management of production activities. A complex approach to the development of business management system (including information technology support processes as a component) is realized by using an enterprise architecture concepts. Creation of IMS on the basis of architectural approach will ensure full transparency of the main and auxiliary industries and provide managing staff of the company with effective tools for decision-making to improve the efficiency of production and business due to the possibility of:

- operational control of product roadmap;

- determination of locations and causes of failures / infringements;

- real-time update of plans and product creation technology on the basis of the real situation;

- evaluation of the performance of individual production units;

- monitoring of deterioration of the technological equipment, engineering systems and networks, condition monitoring of fixed assets.

The development of detailed models of different layers of mining companies architecture is considered to be the promising direction for further research in this field.

\section{References}

1. I.V.Iliyn, Y.L.Levchenko, A.I.Levina, Scientific and technical sheets of St. Petersburg State Polytechnic University1-2 (163), 48-54 (2013) 
2. I.V.Ilyin, O.Yu.Iliashenko, K.M.Makov, K.V. Frolov, St. Petersburg Polytechnic University Journal 5 (228), 107(2015)

3. I.V.Ilin, O.Yu.Iliashenko, A.I. Levina, Procedia Engineering, 165 (2016)

4. I.V.Ilin, O.Yu.Iliashenko, A.I. Levina, Competitive Economic Growth9-10, 768781(2016)

5. V.V.Glukhov, I.V.Ilin, O.Yu. Iliashenko, Springer9870, 512-524(2016)

6. D.V.Kudryavtsev, M.Y.Arzumanyan, L.Y. Grigoryev, Publishing of Polytechnic University, 427 (2014)

7. M.Lankhorst, Springer-Verlag, 338 (2013)

8. MIT Center for Information Systems Research: [Electronic resource]. URL: http://cisr.mit.edu/research/research-overview/classic-topics/enterprise-architecture/

9. Gartner Group, IT Glossary: [Electronic resource]. Access mode: http://www.gartner.com/it-glossary/

10. V.Kondratyev,Eksmo, 1(2007)

11. M.Land, E. Proper, M.Waage, J. Cloo,C.Steghuis, Springer Verlag, 69(2009)

12. G.N. Kalyanov, URL: http://www.vshu.ru/files/IR01a.pdf/

13. The Open Group, The Open Group Architecture Framework(2009)

14. I.V.Ilin, A.I.Lyovina, A.R.Antipin, Results and Experiences, 51-63(2016)

15. Sum of technologies,URL: http://www.summatechnology.ru/projects/all/proektirovanie-integrirovannoy-sistemyupravleniya-proizvodstvom-gorno-obogatitelnogo-kombinata/

16. V.N.Oparin, A.P.Tapsiev, E.P.Rusin, A.M.Freydin, B.P. Badtiev,Institute of Mining, 99 (2007)

17. Engeneering systems,URL: http://www.i-teco.ru/solutions/inzhenernyye-sistemy/ 